\title{
Traffic Safety Evaluation and Accident Prediction of Freeway: Evidence from China
}

\author{
Hongjun XIONG, Yi SHEN*, Liyou FU
}

\begin{abstract}
In recent years, freeway safety accidents occurred frequently, causing serious harm to people's lives and property safety. Therefore, how to evaluate freeway traffic safety and predict the number of accidents scientifically is a practical problem to be solved. The influencing factors of freeway traffic safety could be summarized as human behaviour characteristics, vehicle factors, road factors, environmental factors and traffic safety factors after a systematic analysis. To evaluate traffic safety and predicate freeway accident, using the data of Zhejiang province, China from 2015 to 2019, a freeway safety evaluation system was constructed. The freeway safety level was measured by using hierarchical entropy method, and the future traffic accidents in the sample area were predicted by using the Autoregressive Integrated Moving Average (ARIMA) model. Results show that the traffic safety level of freeway in the sample areas presents a fluctuating upward trend, and has a relatively safe state with a safety level 2. The average error rate is only $0.47 \%$ in the predication of freeway accident, showing a high degree of fitting and accuracy. Based on the above conclusions, this study puts forward the corresponding improvement strategies to provide a scientific basis for the decision-making of the government and transportation departments.
\end{abstract}

Keywords: accident prediction; ARIMA model; freeway; influence factors; safety evaluation

\section{INTRODUCTION}

Freeway is a fully closed, multilane, large flow transportation route for high-speed vehicles and is an important guarantee for the modernization of transportation and the high-speed operation of the city. Freeway plays an important role in promoting the flow of people and materials, in improving people's living standards, and in promoting the rapid development of social productivity. Freeway represents the speed and efficiency of national or regional transportation, and is one of the important symbols to measure the modernization of national economy. At present, more than 80 countries and regions have established freeway network system in the world, with a traffic mileage of more than $230000 \mathrm{~km}$. The freeway development process could be roughly divided into the following four stages: The first stage is the initial stage of development. Due to the slow economic growth, the scale of freeway is limited and people's awareness of freeway is relatively low. The second stage is the rapid development period. With the continuous improvement of people's demand for freeway, the total mileage of traffic increases rapidly with the economic development. The third stage is near saturation period. With the restraint of resources, the growth rate of freeway mileage has slowed down and the road network quality was paid much attention. The fourth stage is a relatively stable period. The development scale of freeway tends to be stable, and depends on the improvement of traffic management level to enhance the operation quality of freeway, indicating the development trend of intelligent transportation system.

Compared with ordinary trunk highway and expressway, freeway has many advantages, such as lane division, direction division, large capacity, low transportation cost and so on, and was considered to be the safest in the world [1]. However, with the development of society and economy, the urban passenger volume and vehicle density were increasing, coupled with the insufficiency of people's management experience and understanding of law in freeway traffic organization, caused a low level of freeway traffic safety and frequent traffic accidents. As the aorta of transportation, freeway safety directly affects the social welfare, property safety, medical insurance, etc. And freeway safety is one of the key factors restricting the development of modern society and economy. Under the background of continuous expansion of freeway coverage and the sharp increase of traffic flow, this study analyses the influence mechanism of freeway traffic safety, clarifies the relationship between various factors and traffic safety, and adopts a reasonable model to evaluate the current freeway traffic safety level comprehensively, which has a great significance to formulate effective measures to improve freeway traffic safety management, avoid traffic accidents and reduce the damage degree.

Studies mainly focused on the normative research of freeway traffic safety, without summarizing and analysing its influencing factors, and seldom explored the regional freeway traffic safety levels, and considered less the time correlation in the prediction of the number of accidents. On the basis of available research results, the influencing factors of freeway traffic safety was systematically analysed, a multidimensional evaluation index system was constructed. Meanwhile, the relevant data of freeway in Zhejiang Province from 2015 to 2019 was adopted, and its traffic safety was evaluated by using the hierarchical entropy method. In addition, the number of traffic accidents in the sample area was predicted by using ARIMA model in this study, to provide support for formulating traffic safety prevention and control measures for the government and traffic management departments, reduce the accident rate, and improve the modern management system of freeway continuously.

\section{LITERATURE REVIEW}

\subsection{Freeway Traffic Safety Factors}

Scholars have conducted an extensive research on the influencing factors of freeway traffic safety. Abdel-Aty, et al. built a real-time freeway accident risk model based on the traffic flow data before the accident happened [2]. The results showed that some traffic flow variables affected the accident rate significantly, and the use of dynamic traffic control system could improve traffic safety effectively. Chen, et al. analysed the heterogeneity of vehicle, road, driver and other factors influencing the freeway traffic 
accidents in mountain and non-mountain areas, and found that the freeway traffic accidents in mountain areas were more serious, mainly due to the lack of speed limit, small curve radius and large downhill gradient of freeways [3]. $\mathrm{Li}$, et al. analysed the influencing factors of freeway traffic accident mortality systematically, and found that bad weather, combined curve and slope sections, and speeding were the main influencing factors [4]. Thefilatos et al. analysed the traffic safety of urban arterial freeways in Athens by using Bayesian logistic regression model, and found that both the traffic flow and weather conditions affected the accident incidence and severity, and the former had a more significant impact [5]. Heqimi, et al. analysed the freeway traffic accident data using the negative binomial regression model, and found that there was a significant positive correlation between the annual snowfall and freeway traffic accidents [6].

\subsection{Freeway Traffic Accident Prediction}

In terms of freeway traffic accident prediction, many studies have been made. Ahmed et al. brought the accident prone probability, temporal and spatial correlation of specific road sections into a research framework, and analysed the severity of traffic accidents using logistic model and finite mixture model [7]. Deublein, et al. constructed a multivariate negative binomial regression model based on Swiss freeway traffic accident data, and estimated the model coefficients by using Bayesian network, which further improved the accuracy of freeway traffic accident prediction results [8]. Zhang, et al. incorporated the driver's age, gender, seat position and other factors into the freeway traffic accident prediction model, further revealed the mechanism of traffic accidents, and provided a new perspective for traffic safety policy system [9]. Gao, et al. constructed a freeway traffic accident risk prediction model based on the continuous data, tested the full sample and sampling data by using random forest and logical regression method respectively [10]. It is found that the modelling results were more effective based on the full sample data, and the traffic accident risk prediction ability was improved by $13 \%$.

To sum up, it was not difficult to find that many studies have been made on freeway traffic safety. In terms of influencing factors, the study has gradually developed from a single factor to multi factors. In terms of econometric analysis, the study has gradually changed from a single descriptive analysis to a multivariable and complex modelling and calculation analysis. The existing research provided a solid foundation for this study. However, there were some deficiencies. The influencing factors of freeway traffic safety mainly included driver's factors, road factors, and natural environment factors, etc., but lack of systematic analysis and summary. The traffic safety evaluation index focused on the number of accidents, without taking the macro and micro factors such as people, vehicles, road, environment and traffic safety management into the evaluation system. Due to the restriction of freeway traffic accident data collection and integration, few continuous data models were constructed and analysed, and the weight calculation methods mainly focused on AHP, accident rate method and other subjective weighting methods, which might lead to the deviation of evaluation results. The application and popularization of freeway traffic accident prediction model were insufficient, which could not provide a effective guidance for freeway accident risk warning and traffic safety.

\section{CONSTRUCTION OF FREEWAY TRAFFIC SAFETY EVALUATION SYSTEM}

Freeway traffic safety was affected by many factors, which could be classified into five ones, such as human behaviour characteristic factors, vehicle factors, road factors, environmental factors and traffic safety management factors. And a multi-dimensional highway traffic safety evaluation system could be established based on them.

\subsection{Influencing Factors of Freeway Traffic Safety 3.1.1 Human Behaviour Characteristic Factors}

People played a leading role in the freeway traffic system, including motor vehicle drivers, non-motor vehicle drivers and pedestrians, who affected the traffic safety crucially. On the one hand, people had a high degree of flexibility and autonomy, and could make a rapid response according to the freeway traffic information and road condition changes [11]. However, people's physiological characteristics and subjective initiatives restricted their behaviour performance at the same time. There was a certain time lag between their receiving the instructions to change the driving state of the vehicle and their reaction and execution. Especially, it was easier to produce the phenomenon of functional depression after drinking or driving for a long time [12], which reduced the visual characteristics and judgment ability during the driving period, and then affected the stability of vehicle operation. On the other hand, drivers might have illegal driving on the freeway, which would bring traffic safety risks. Among them, failure to give way as required, driving without license, speeding, drunk driving and reverse driving, etc. caused the most accidents and injuries.

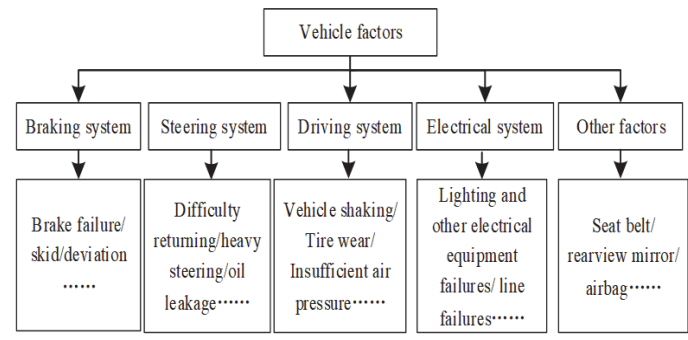

Figure 1 Vehicle factors affecting freeway traffic safety

\subsubsection{Human behaviour Characteristic Factors}

Vehicle was an important component of traffic system, closely related to freeway traffic safety. Its influencing factors included brake system, steering system, driving system, electrical system and so on, as shown in Fig. 1.

Vehicle braking was the prerequisite to ensure safe parking [13]. It focused on the analysis of the relationship between vehicle braking system and freeway traffic safety. The vehicle would continue to run for a certain distance after the drivers took braking measures. Traffic accidents might happen in the course of running. Therefore, it is 
called the unsafe braking distance, which could be expressed by the following Eq. (1):

$$
L=\frac{v_{0} t_{1}}{3.6}+\frac{v_{0}\left(t_{2}+\frac{t_{3}}{2}\right)}{3.6}+\frac{v_{0}^{2}}{254 g}
$$

Among them, $L$ is the unsafe braking distance. $v_{0}$ is the driving speed. $t_{1}$ is the reaction time of driver. $t_{2}$ and $t_{3}$ are the transmission delay time and braking force growth time of braking system respectively. $\left(t_{2}+t_{3}\right) / 2$ is the time required for system coordination, and $\gamma$ is the friction coefficient between vehicle and road surface.

It is learnt that the unsafe braking distance was not only related to the driving speed and response time of drivers, but also to the structure of the brake device and the adhesion coefficient of freeways. The traffic safety accidents such as rear end collision and deviation caused by vehicle braking often occur, especially in the natural environment such as rain and snow. The $\gamma$ friction coefficient was reduced, which led to the wheel locking when the vehicle was braking in emergency, and increased the unsafe braking distance.

With the development of automobile manufacturing industry, transportation equipment manufacturing industry, the traffic safety problems caused by vehicle designs are weakened, but vehicle factors are still one of the main factors affecting traffic safety problems in high speed driving.

\subsubsection{Road Factors}

There are differences in freeway traffic safety conditions in various terrain areas, as tunnels, sharp turns, long slopes and unequal road height, which were more likely to cause traffic accidents, whose influencing paths included traffic accidents caused by the freeway conditions directly, and the effects on drivers, vehicles and environment resulting from the freeway conditions indirectly, as shown in Fig. 2.

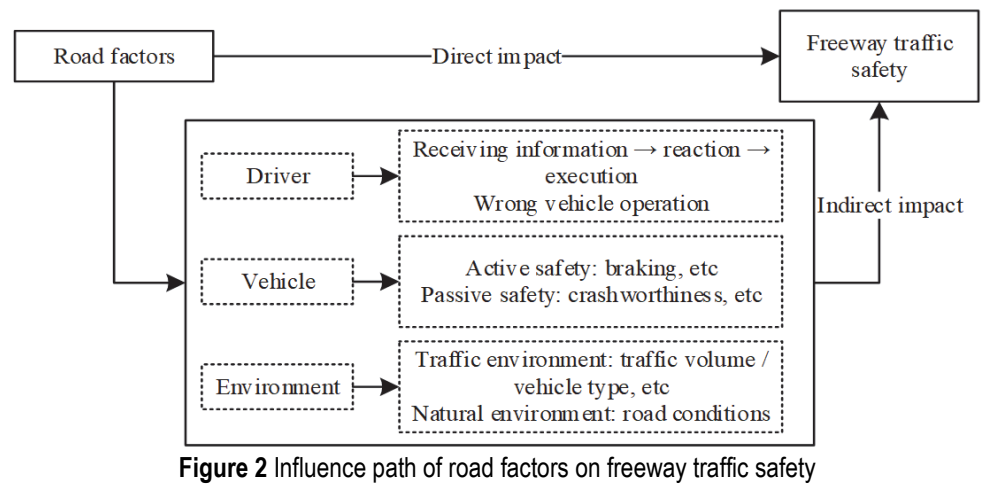

Road is one of the main factors affecting drivers' driving judgment, which is related to traffic safety directly, and even plays a decisive role under some specific conditions. More specifically, it includes the following four aspects.

(1) Route design. The route design directly reflected the external contour of the road and traffic state, and the straight line was the most basic element. When driving for a long time, drivers would produce visual fatigue, increased the reaction time, resulting in safety risks [14]. It was found that the curvilinear degree had an inverse correlation with traffic safety, and about $1 / 3$ of safety accidents occurred on horizontal and vertical curves [15].

(2) Subgrade and pavement. Subgrade mainly played its role through shoulder, intermediate belt and cross section. Pavement was a component of freeway, which had high requirements for anti-sliding, flatness and structural strength.

(3) Sight distance, terrain and ground objects would bring visual obstacles to drivers, which led to the sight distance failure to reach the sight range. Plane curve section, convex section and concave deformation slope section were typical forms of traffic accidents [16].

(4) Road type and traffic engineering. The former could be classified according to the number of freeway lanes, lane width, new or old, while the latter was the key factor of freeway driving safety, efficiency and comfort, such as protective facilities, road monitoring and communication system, which played an important role in ensuring traffic safety.

\subsubsection{Environmental Factors}

Environmental factors were relatively complex and comprehensive. On the basis of in-depth analysis, this study divided them into three aspects: traffic flow, vehicle types and natural environment.

(1) Traffic flow. Traffic flow was the vehicles passing through a section of freeway in a certain period of time. The ratio between traffic flow and freeway capacity reflected the service level of freeway. The higher the ratio was, the greater the saturation of traffic flow, which was closely related to traffic safety. According to service level of China's freeway issued by the Ministry of Transport of $\mathrm{PRC}$ and some research results, the traffic saturation could be divided into the following three categories. The saturation was at a low level, in which it was easy to overtake due to its large degree of freedom. The saturation at a medium level, it is difficult to overtake due to its continuous and stable traffic flow and certain gap. The saturation at a high level, it is very difficult to overtake due to continuous and extremely unstable traffic flow and a very small gap. In the congested road sections, traffic accidents were more likely to happen, because the drivers were affected by the increase of traffic volume, leading to a failure to give way as required or keep a safe distance. If 
the traffic flow could not be controlled and evacuated in time, freeway traffic paralysis on the freeway would happen to cause traffic accidents.

(2) Vehicle types. The maximum speed of China's freeway was $120 \mathrm{~km} / \mathrm{h}$ and the minimum speed $60 \mathrm{~km} / \mathrm{h}$, which had certain requirements for vehicle performance. However, the differences in the performance of various types of vehicles would produce horizontal or vertical interference and affect traffic safety. Taking large vehicles as an example, their impacts on traffic safety were mainly reflected in the following aspects. Firstly, the braking performance was poor because the great inertia of large vehicles would lead to a longer unsafe braking distance, and the rear end collision, collision and deviation of vehicles would also cause severe traffic accidents. Secondly, the operation stability was poor. Restricted by the technical performance of chassis [17], the stability of large vehicles in lateral lane change and longitudinal driving became poorer, shift and sway might happen in the process of a high speed freeway driving. Thirdly, the speed was discrete. The average speed of large vehicles was significantly lower than that of other types of vehicles, and the speed difference between large vehicles and small vehicles could reach up to $60 \mathrm{~km} / \mathrm{h}$. It was easy to cause the imbalance of vehicle flow when large vehicles changed frequently in the state of following, overtaking, free, following. In addition, large vehicles need higher dynamic safety distance and sight distance due to the differences of vehicle structure and driving flexibility, which further increased the adverse impacts on traffic safety in the case of large traffic flow.

(3) Natural environment. Complex weather as rain, snow and fog, would lead to the deterioration of freeway driving conditions [18], and the reduction of visibility, traffic capacity, wet road surface, lower adhesion coefficient between vehicles and road surface, etc. It was very easy to cause traffic accidents such as sideslip, rollover, brake out of control, when the vehicle was turning or braked in a sudden, especially in long, downhill sections in mountainous areas, which required a higher psychological and physical quality for the drivers [19].

\subsubsection{Traffic Safety Management Factors}

Freeway traffic system was a complex system with dynamic changes, and traffic safety management was the continuity of freeway development, which needed the coordination and cooperation of participants from various industries. Thus, the traffic safety management was the most extensive and complex factor involved in the traffic system.

Traffic safety management could be divided into two categories: the first one was the management of participants, including drivers, passengers and pedestrians. Through the establishment of sound traffic safety laws and regulations and management system, such as increasing the traffic safety publicity and education, standardizing qualification recognition and qualification management, enhancing highway operation management, and punishing violations of traffic regulations, the behaviour of participants could be regulated. The second one was the management of the objects, involving in vehicles, roads and traffic environment, which were the indirect factors that affect the traffic safety. In terms of vehicles, the management includes regulating the production, maintenance and scrapping standards of vehicles, checking regularly and managing the safety and technical characteristics of vehicles. In terms of roads, it includes the development of road design and construction standards, maintenance and repair standards, road facilities transformation and management in operation, etc. In terms of traffic environment, it includes reasonable guidance and control of traffic volume, maintenance and management of freeway landscape and greening, warning, alarm and emergency system for disaster or accident prevention under bad weather environment. Therefore, traffic safety management infiltrated into other factors of the traffic system and affected freeway traffic safety through interaction, as shown in Fig. 3.

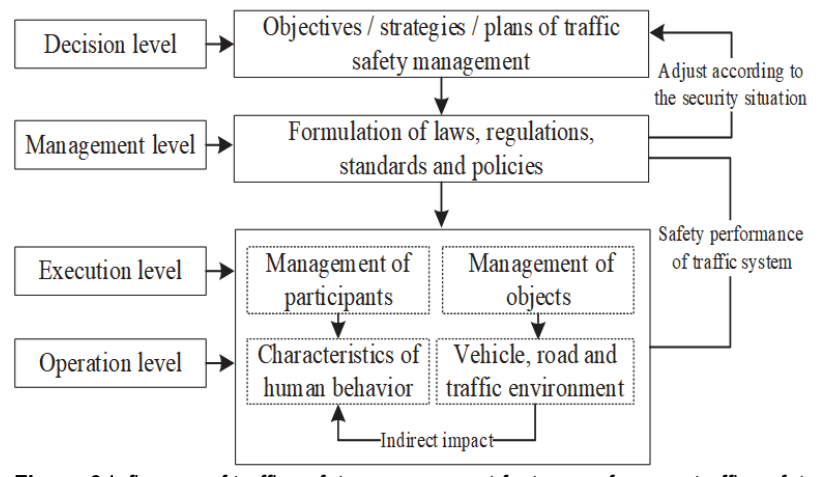

Figure 3 Influence of traffic safety management factors on freeway traffic safety

\subsection{Freeway Traffic Safety Evaluation Index System}

Scientific and reasonable evaluation index was a key to determine the objectivity and accuracy of freeway traffic safety evaluation results.

On the basis of the above and some scholar's research on freeway traffic safety and screening the indicators according to the principles of comparability, representativeness and measurability, the paper constructed a set of freeway traffic safety evaluation index system, as shown in Tab. 1 .

\subsection{Freeway Traffic Safety Evaluation Model}

The commonly used methods of traffic safety evaluation include the following three categories: one is quantitative analysis method, such as accident rate method, fuzzy comprehensive evaluation method, entropy weight method, rough set method, etc. The other is qualitative analysis method, such as comparative analysis method, causal analysis method, etc. The third is the combination of quantitative and qualitative methods, such as analytic hierarchy process, fuzzy comprehensive evaluation method based on hierarchy process, etc. Based on the comprehensive comparison of the advantages and disadvantages of each evaluation method, the hierarchical entropy method is finally used to measure the traffic safety level of freeway, and a few qualitative indicators are measured by the mean value of the number of samples, so that the evaluation results are both subjective and objective. Due to the difference of numerical value and 
dimension in the original data of traffic safety, it is standardized, as shown in Eq. (2):

$r_{i j}=\frac{\mathrm{x}_{i j}-\min _{j}\left(x_{i j}\right)}{\max _{j}\left(x_{i j}\right)-\min _{j}\left(x_{i j}\right)}$

Firstly, the AHP method is used to carry out subjective weight, which is counted as $\alpha_{i}$, and then the total weight coefficient of each index is determined by entropy weight method, which is counted as $w_{i}$. The evaluation process based on the level entropy is as follows:

(1) Define entropy. The calculation formula of entropy $h$ of the $i$-th index is shown in Eq. (3):

$$
\begin{aligned}
& h_{i}=-k \sum_{j=1}^{n} f_{i j} \ln f_{i j} \\
& f_{i j}=r_{i j} / \sum_{j=1}^{n} r_{i j}
\end{aligned}
$$

\begin{tabular}{|c|c|c|}
\hline Target layer & Criterion layer & Index layer \\
\hline \multirow[b]{2}{*}{ Human factor } & Driver's driving skills & $\begin{array}{l}\text { Average driving age of drivers } \\
\text { Driver's safety knowledge level }\end{array}$ \\
\hline & Traffic safety awareness & $\begin{array}{l}\text { Fatigue driving rate } \\
\text { Growth rate of traffic violations } \\
\text { Driver traffic safety training rate }\end{array}$ \\
\hline \multirow{3}{*}{ Vehicle factor } & Braking system & Vehicle emergency braking distance \\
\hline & Safety performance & $\begin{array}{l}\text { Proportion of overloaded vehicles } \\
\text { Configuration of vehicle emergency rescue equipment }\end{array}$ \\
\hline & Warranty level & $\begin{array}{l}\text { Vehicle scrap rate } \\
\text { Vehicle inspection rate }\end{array}$ \\
\hline \multirow{4}{*}{ Road factor } & Route design & Horizontal and vertical combination \\
\hline & Pavement and subgrade & $\begin{array}{l}\text { Pavement integrity rate } \\
\text { Failure rate of dangerous road sections }\end{array}$ \\
\hline & Sight distance & $\begin{array}{l}\text { Maximum longitudinal gradient } \\
\text { Traffic signs and signal completion rate }\end{array}$ \\
\hline & Traffic engineering & $\begin{array}{l}\text { Isolation and protection facilities } \\
\text { Traffic signs and line facilities } \\
\text { Traffic information feedback and command facilities }\end{array}$ \\
\hline \multirow{3}{*}{ Environmental factor } & Freeway traffic volume & $\begin{array}{l}\text { Traffic volume } \\
\text { Traffic density } \\
\end{array}$ \\
\hline & Vehicle composition & $\begin{array}{l}\text { Proportion of large vehicles } \\
\text { Speed difference between big and small vehicles }\end{array}$ \\
\hline & Natural environment & $\begin{array}{l}\text { Annual bad weather } \\
\text { Probability of natural disasters }\end{array}$ \\
\hline \multirow[t]{2}{*}{ Traffic safety management } & Management system & $\begin{array}{l}\text { Traffic safety responsibility system } \\
\text { Professional competence of managers } \\
\text { Coverage rate of traffic violation detection and record system }\end{array}$ \\
\hline & Accident rescue system & $\begin{array}{l}\text { Emergency rescue system } \\
\text { Improvement rate of freeway emergency plan }\end{array}$ \\
\hline Target layer & Criterion layer & Index layer \\
\hline \multirow[b]{2}{*}{ Human factor } & Driver's driving skills & $\begin{array}{l}\text { Average driving age of drivers } \\
\text { Driver's safety knowledge level }\end{array}$ \\
\hline & Traffic safety awareness & $\begin{array}{l}\text { Fatigue driving rate } \\
\text { Growth rate of traffic violations } \\
\text { Driver traffic safety training rate }\end{array}$ \\
\hline
\end{tabular}

Table 1 Freeway traffic safety evaluation index system

(2) Entropy weight is defined. The calculation formula of entropy weight $w$ of the $i$-th index is shown in Eq. (4):

$$
w_{i}=\frac{1-h_{i}}{m-\sum_{i=1}^{m} h_{i}}\left(0 \leq w_{i} \leq 1, \sum_{\mathrm{i}=1}^{m} w_{i}=1\right)
$$

(3) According to the subjective weight $\alpha_{i}$ and objective weight $w_{i}$ calculated in the previous article, the comprehensive weight coefficient $\beta$ is determined as shown in Eq. (5):

$$
\beta_{\mathrm{i}}=\frac{\alpha_{i} w_{i}}{\sum_{i=1}^{n}\left(\alpha_{i} w_{i}\right)}
$$

(4) Construct the evaluation model of hierarchical entropy of traffic safety, as shown in Eq. (6): $\phi_{\mathrm{t}}=\sum_{i=1}^{n} \beta_{i} y_{t i}$

Among them, $y_{e i}$ is the result of the standard value of the $i$-th evaluation index in year $t$ processed by the percentage system, and $\varphi_{t}$ is the final evaluation value.

\section{RESULTS ANALYSIS AND DISCUSSION 4.1 Model Application}

Taking Zhejiang Province of China as the research object, this paper uses case analysis method to obtain relevant data from 2015 to 2019 by investigating and collecting accident statistics, traffic flow investigation centre, road construction design documents, etc. of Traffic Management Bureau of public security department, traffic police department, and divides highway traffic safety into the following five levels: 
Safety (Level 1, evaluation value $0.8 \sim 1$ ), relatively safe (Level 2, evaluation value 0.6 0.8), general (Level 3, evaluation value $0.4 \sim 0.6$ ), relatively unsafe (Level 4 , evaluation value $0.2 \sim 0.4$ ), unsafe (Level 5 , evaluation value $0 \sim 0.2$ ). Based on the evaluation model of hierarchical entropy, the comprehensive evaluation results of freeway traffic safety in Zhejiang Province are obtained, as shown in Tab. 2.

Table 2 Comprehensive evaluation value of freeway traffic safety in Zhejiang Province of China in 2015-2019

\begin{tabular}{|c|c|c|c|c|c|}
\hline Year & 2015 & 2016 & 2017 & 2018 & 2019 \\
\hline $\begin{array}{c}\text { Evaluation } \\
\text { value }\end{array}$ & 0.53 & 0.58 & 0.64 & 0.62 & 0.72 \\
\hline Safety level & $\begin{array}{c}\text { The third } \\
\text { level } \\
\text { (common) }\end{array}$ & $\begin{array}{c}\text { The third } \\
\text { level } \\
\text { (common) }\end{array}$ & $\begin{array}{c}\text { The } \\
\text { second } \\
\text { level } \\
\text { (safer) }\end{array}$ & $\begin{array}{c}\text { The } \\
\text { second } \\
\text { level } \\
\text { (safer) }\end{array}$ & $\begin{array}{c}\text { The } \\
\text { second } \\
\text { level } \\
\text { (safer) }\end{array}$ \\
\hline Ranking & 5 & 4 & 2 & 3 & 1 \\
\hline
\end{tabular}

From Tab. 2, it can be learnt that the traffic safety level of freeway in Zhejiang Province shows a fluctuating upward trend in general. In 2018, the freeway traffic safety level in Zhejiang Province was maintained at level 2, but the safety evaluation value declined, because of many major traffic safety accidents that happened. In 2019, the freeway traffic safety level still stayed at level 2, but the safety evaluation value was greatly improved compared with the previous year, mainly due to the continuous improvement of the safety factors as people, vehicles, roads, environment and management around the goals of safer traffic and smoother roads set by Zhejiang Provincial Highway Traffic Police Corps (ZPHTPC). Meanwhile, ZPHTPC established a police medical cooperation with 30 medical institutions, exploring the pilot mechanism of "nearby and superior" medical service, thus the traffic safety management level was improved significantly; the traffic safety prevention and control achieved remarkable results. In addition, Zhejiang Province has promoted the comprehensive management of road traffic safety, such as improving freeway safety protection, implementing the responsibility of traffic safety, supervising the management of hidden danger sections, and normalizing the strict control of traffic violations, so as to accelerate the modern freeway traffic management.

\subsection{Traffic Accident Prediction Based on ARIMA model}

ARIMA model is the most effective for short-term prediction, which can reasonably predict and simulate the future value according to the past value and present value of variable series. Assuming that the time series of traffic accidents is $Y$, the ARIMA model of order $(p, q)$ is shown in Eq. (7):

$$
\begin{gathered}
Y_{\mathrm{t}}=\phi_{1} Y_{t-1}+\phi_{2} Y_{t-2}+\ldots+\phi_{p} Y_{t-p}+\varepsilon_{t}+f_{1} \varepsilon_{t-1}+f_{2} \varepsilon_{t-2}+\ldots+f_{q} \varepsilon_{t-q} \\
\phi_{p}(L) Y_{t}=f_{q}(L) \varepsilon_{t}
\end{gathered}
$$

Among them, $\varphi_{p}$ and $f_{q}$ respectively represent the characteristic polynomial of $p$ and $q$ of $L, p$ is the autoregressive lagged term, $q$ is the moving average term, $\varepsilon$ is the error term. If $Y$ is a non-stationary sequence, the process of transforming into a stationary sequence by $\mathrm{d}$ difference can be regarded as $\operatorname{ARIMA}(p, d, q)$ model, and then get the Eq. (8):

$\nabla^{\mathrm{d}} Y_{\mathrm{t}}=(1-L)^{d} Y_{t}$

The original time series can be expressed by Eq. (9):

$$
\begin{gathered}
\phi_{p}(L)(1-L)^{d} Y_{t}=f_{q}(L) \varepsilon_{t} \\
\phi_{p}(L) \nabla^{\mathrm{d}} Y_{t}=f_{q}(L) \varepsilon_{t}
\end{gathered}
$$

Therefore, taking the historical data of traffic accidents in Zhejiang Province (2000-2019) as a known series, considering the availability of the data, taking the number of road traffic accidents as a proxy variable, and using Stata14.0 to test, it is found that the new series formed by the first-order difference fluctuates near zero, which is a stationary time series, and the $p$ value of the statistics is 0.003 , so $d=1$ is selected. In order to determine the optimal order of ARIMA model [20], through autocorrelation and partial correlation test, it is found that both of them fall into the range of double standard deviation from the first order (as shown in Tab. 3). Therefore, considering the value of $p$

\begin{tabular}{|c|c|c|c|c|c|c|}
\hline autocorrelation & partial correlation & \multicolumn{2}{|c|}{$\mathrm{AC}$} & PAC & Q-Atat & Prob \\
\hline- & \multirow{5}{*}{-} & 1 & 0.118 & 0.116 & 0.309 & 0.000 \\
\hline \multirow[t]{4}{*}{. } & & 2 & 0.145 & 0.054 & 0.800 & 0.000 \\
\hline & & 3 & -0.004 & -0.146 & 0.801 & 0.000 \\
\hline & & 4 & -0.077 & -0.095 & 0.959 & 0.000 \\
\hline & & 5 & -0.138 & -0.183 & 1.504 & 0.000 \\
\hline
\end{tabular}
and $q$ as 1 , we test according to the principle of information minimization, and finally establish ARIMA $(1,1,1)$ model.

Table 3 Correlation results of first order difference sequences

Based on the above, the parameters of ARIMA (1, 1, 1) model of traffic accidents are estimated. The $p$ value of AR autoregression and Ma moving average is less than 0.01 . In order to further verify the rationality of the model, the white noise analysis of residual sequence is used to determine whether the model fully reflects the data information and whether the residual sequence is composed of unrelated random variables. Assuming that there is no $p$-order autocorrelation, the $Q$-statistics is shown in Eq. (10):

$$
Q=N(N+2) \sum_{\mathrm{j}=1}^{p} \frac{r_{\mathrm{j}}^{2}(e)}{N-j}
$$

Among them, $N$ is the total sample size, $r_{j}^{2}(e)$ is the $j$-order autocorrelation coefficient, and $\mathrm{p}$ is the lag order. 
The test results accept the original hypothesis that the residual term is "no autocorrelation", which indicates that the random error term formed by ARIMA model is a white noise series, and the model has a good fitting degree. The fitting curve is shown in Fig. 4. The dotted line is the upper and lower line of control, the solid line is the actual and predicted value of traffic accident, the horizontal axis represents the time, and the vertical axis represents the observed value.

From Fig. 4, it could be learnt that the fitting effect between the actual freeway traffic accidents in Zhejiang Province and the predicted results was good, which could directly reflect the future trend and evolution direction of traffic accidents, and had a guiding significance for traffic safety prevention and control. According to the fitting results, the time series of traffic accidents in Zhejiang province showed a downward trend. In order to verify the practical significance of ARIMA model, the error between the real and predicted value was compared and analysed. It was found that the average error rate was only $0.47 \%$, indicating that it had a high accuracy.

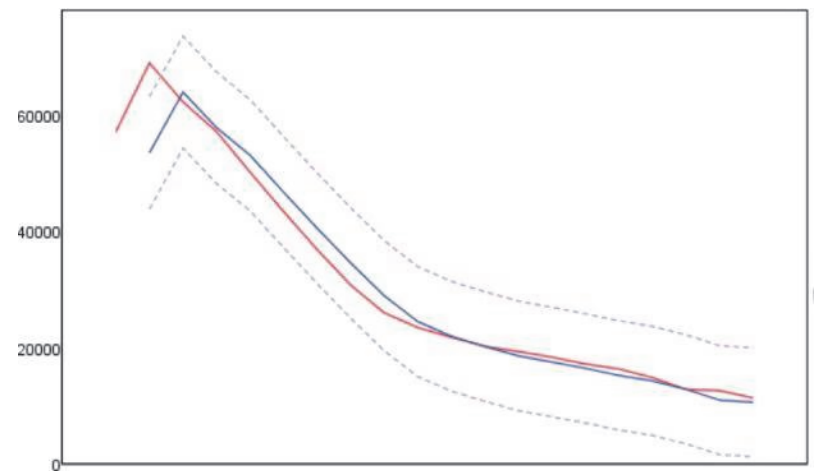

Figure 4 The fitting chart of the return series of various economic sectors in China (Note: The left full line is the observed value, the middle full line is the fitting value, and the two dashed lines represent UCL and LCL respectively)

\section{CONCLUSION}

In this study, various influencing factors of freeway traffic safety were systematically analysed, a multidimensional evaluation index system was constructed, freeway traffic safety in Zhejiang Province was evaluated by using hierarchical entropy method, and some forecasts for traffic accidents were made through ARIMA model. The main conclusions were as follows.

(1) Freeway traffic safety system was a dynamic and complex system, whose main influencing factors included human behaviour characteristics, vehicle factors, road factors, environmental factors, traffic safety management factors and so on

(2) Taking Zhejiang Province as the research sample, this study made an empirical analysis by using the hierarchical entropy method. The freeway traffic safety level in Zhejiang Province presented a fluctuating upward trend, and has entered a relatively safe state, with a safety level 2. Although the freeway traffic safety level in Zhejiang Province has gotten better, it still required much improvement. The relevant departments should strengthen the management of people, roads etc., conduct some special researches on the causes of accidents in accident black spots, increase the publicity, supervision and punishment of freeway traffic safety, and carry out targeted transformation of road conditions. At the same time, the relevant departments should also continue to promote the comprehensive management of freeway traffic safety, improve the co-construction and public governance mechanism of traffic safety further, and strengthen the construction of traffic safety management system.

(3) This study predicted the traffic accidents happening in Zhejiang Province by using ARIMA model, and tested the fitness and prediction accuracy of the model. It was found that the average error rate is only $0.47 \%$. The conclusions could be used as a reference for the freeway traffic safety evaluation and traffic planning in Zhejiang Province, and were conducive to achieve the goals of safer traffic, smoother roads and more satisfactory people.

In view of the availability of data, this study only measured the freeway traffic safety level in Zhejiang Province from 2015 to 2019, and only predicted the traffic accidents by using ARIMA model, which was relatively insufficient. In the following, the longer time span data would be selected for testing, and other prediction models would be verified, so as to improve the accuracy of conclusions further.

\section{Acknowledgements}

This study was supported by Shanghai Education Science Research Project (No. C2021299).

\section{REFERENCES}

[1] Jorgensen, F. \& Larsen, T. W. (1999). Optimal use of warning signs in traffic. Accident Analysis and Prevention, 31(5), 726-738. https://doi.org/10.1016/S0001-4575(99)00036-6

[2] Abdel-Aty, M., Uddin, N., \& Pande, A. (2005). Split models for predicting multivehicle crashes during high-speed and low-speed operating conditions on freeways. Transportation Research Record Journal of the Transportation Research Board, 1908(1), 51-58. https://doi.org/10.1177/0361198105190800107

[3] Chen, J., Hu, Q., \& Zhu, Y. (2017). Comprehensive evaluation model of highway traffic safety considering subjective and objective factors. Journal of Safety Science of China, 27(5), 36-40.

[4] Li, M., Wang, Y., Zhang, W., et al. (2015). Identification of significant influencing factors of traffic fatality accidents on expressways in mountainous areas. Chinese Journal of Safety Sciences, 25(05), 126-130.

[5] Theofilatos, A. (2017). Incorporating real-time traffic and weather data to explore road accident likelihood and severity in urban arterials. Journal of Safety Research, 61(6), 9-21. https://doi.org/10.1016/j.jsr.2017.02.003

[6] Heqimi, G., Gates, T. J., \& Jonathan, J. K. (2018). Using spatial interpolation to determine impacts of annual snowfall on traffic crashes for limited access freeway segments. Accident Analysis and Prevention, 121(12), 202-212. https://doi.org/10.1016/j.aap.2018.09.014

[7] Ahmed, M. M. (2012). The Viability of Using Automatic Vehicle Identification Data for Real-Time Crash Prediction. IEEE Transactions on Intelligent Transportation Systems, 13(2), 459-468. https://doi.org/10.1109/TITS.2011.2171052

[8] Deublein, M., Schubert, M., Adey, B.T., García de Soto, B. (2015). A Bayesian network model to predict accidents on Swiss freeways. Infrastructure Asset Management, 2(4), 145-158. https://doi.org/10.1680/jinam.15.00008

[9] Zhang, H., Ma, L., Yu, H., et al. (2016). Analysis of risk factors of traffic accident death based on inherent matching data. Traffic Information and Safety, 34(5), 61-67. 
[10] Gao, Z., Gao, Y., Yu, R., et al. (2018). Prediction model of road traffic accident risk under continuous data environment. Chinese Journal of highways, 31(4), 280-287.

[11] Chen, G. \& Wang,H. (2020). Dynamic braking torque compensation of driving robot vehicle. Chinese Journal of Highways, 33(2), 181-190.

[12] Du, C., Yu, J., Zhong, H., et al. (2015). Operating mechanism and set pair analysis model of a sustainable water resources system.Frontiers of Environmental Science \& Engineering, 9(2), 288-297.

[13] Sun, M., Zhao, N., \& Liu, S. (2016). Analysis on traffic accidents and linear characteristics of continuous long and steep downhill of Expressway. Road Traffic and Safety, 16(4), 61-64.

[14] Ma, C., Zhang, S., Ma, Z., et al. (2018). Nonlinear negative binomial prediction model of highway traffic accidents. Chinese Journal of Highways, 31(11), 180-189.

[15] Zhao, S., Li, Y., \& Yu, Q. (2015). Vehicle stability control based on chassis multi subsystem coordinated control. Journal of Transportation Engineering, 15(4), 77-85.

[16] Brijs, T., Karlis, D., \& Wets, G. (2008). Studying the effect of weather conditions on daily crash counts using a discrete time-series model. Accident Analysis \& Prevention, 40(3), 1180-1190. https://doi.org/10.1016/j.aap.2008.01.001

[17] Hu, Q. X., Yang, Y., \& Shi, W. D. (2020). Cavitation simulation of centrifugal pump with different inlet attack angles. International Journal of Simulation Modelling, 19(2), 279-290. https://doi.org/10.2507/IJSIMM19-2-516

[18] Zeng, Q. \& Huang, H. (2014). A stable and optimized neural network model for crash injury severity prediction. Accident Analysis and Prevention, 73(1), 351-358. https://doi.org/10.1016/j.aap.2014.09.006

[19] Salazar-Lozano, M. \& Medina-Murua, P. M. C. A. (2021) Low-cost $3 \mathrm{~d}$ modelling of a go-karting circuit using drone based photogrammetry. DYNA, 96(1), 73-78. https://doi.org/10.6036/9790

[20] Šindelar, J. (2019). Sales forecasting in financial distribution a comparasion of quantitative forecasting methods. Journal of Financial Services Marketing, 24(3), 69-80. https://doi.org/10.1057/s41264-019-00068-3

\section{Contact information:}

Hongjun XIONG, PhD

School of Business, Shanghai Dianji University,

300 Shuihua Road, Pudong New Area District, Shanghai, 201306, China

E-mail:759329303@qq.com

Yi SHEN, PhD

(Corresponding author)

Higher Education Research Institute

Shanghai University of Engineering Science,

333 Longteng Road, Songjiang District, Shanghai, 201620, China

E-mail: hnshenyi1990@163.com

Liyou FU, Prof. PhD

School of Business, Shanghai Dianji University,

300 Shuihua Road, Pudong New Area District, Shanghai, 201306, China

E-mail: fuliyou@163.com 